\title{
An Empirical Study of Instant Messaging (IM) Behavior Using Theory of Reasoned Action
}

\author{
Alan Peslak \\ Penn State University \\ Wendy Ceccucci \\ Quinnipiac University \\ Patricia Sendall \\ Merrimack College
}

\begin{abstract}
Instant messaging (IM) as a form of communication offers unique advantages to traditional email communication centered mostly on its immediacy. Levels of IM use are significantly less than email especially in business organizations. In order to understand IM behavior and encourage its adoption, this manuscript explores IM behavior using the Ajzen \& Fishbein (1980) model of human behavior known as Theory of Reasoned Action (TRA). Attitude toward IM and "subjective norm" are positively associated with intention to use instant messaging. The TRA model can be used to predict and understand the usage of instant messaging in the target population.
\end{abstract}

Keywords: Theory of Reasoned Action, TRA, instant messaging, factor analysis, structural equation modeling.

\section{Introduction}

One of the most important means of communication for young people today is instant messaging. Instant messaging is generally defined as a form of communication where text messages can be exchanged synchronously between users via a web-based client interface. Each user downloads a client to his/her personal computer, creates an account with an IM provider who acts as a clearing house for communications, and then logs in to this IM provider. By logging in, a user establishes a "presence" in the IM provider system and other users of the system are notified of the user's presence. This notification is made available to other users who are logged on to the system at that time and who have previously accepted and exchanged messages (becoming "buddies" or some other such category). The software shows who is available, at which point the user selects an individual with whom they would like to exchange a message, and the message is typed in an easy to use interface and sent. Responses are facilitated through the interface as well. In this way, messages can be simply exchanged between available parties (Wilkins, 2007). Ilie, Van Slyke, Green and Lou (2005) calls it a "private chat room" (p. 18).

Instant messaging as a form of communication offers unique advantages to traditional email communications, centered mostly on its immediacy. But levels of IM use are 
significantly less than email usage, especially in business organizations. This study is an attempt to understand IM behavior and encourage its adoption, by exploring the instant messaging behavior using the Ajzen and Fishbein (1980) model of human behavior known as Theory of Reasoned Action (TRA). Specifically, findings reveal that both attitude toward instant messaging and "subjective norm" are positively associated with intention to use IM. In addition, intention influences use of instant messaging. The TRA model provides a strong fit with the overall data and can be used to predict and understand the usage of instant messaging in the target population. Specific recommendations to increase IM usage are proposed.

\section{Motivation for Study}

In 2003, the Giga Information Group, a market research firm, estimated that IM would become a mission-critical tool" by the end of 2004. Giga also predicted that the enterprise IM market would "grow 200 percent annually" (Lawton, 2003, p. 14). In a survey completed by Pew Internet Organization, only $12 \%$ of Internet users employed the Internet for instant messaging versus $45 \%$ who were using the Internet for email (Rainie \& Horrigan, 2005). Moreover, while nearly all companies use email, only $35 \%$ of organizations use instant messaging (AMA, 2006). This is despite the fact that a study of users of both email and instant messaging preferred instant messaging because the advantages of IM are "conveying emotions, building relationships, and ease of use" (Lancaster, Yen, Huang, \& Hung, 2007, p. 5).

The disparity between email and IM use varies by age. Instant messaging has been rapidly accepted and adopted by individuals between the ages of 8 and 28. But IM as a form of communication is growing in popularity and is becoming more prevalent in the workplace. A study done by Pew Internet \& American Life Project found that $21 \%$ of individuals use IM at work for purposes both personal and business-related. Goldsborough (2004) suggests that "business people use IM for collaboration" (p. 36) but that business is only $10 \%$ of IM users. Nevertheless, Wilkins notes that $77 \%$ of atwork IM users "feel that IM has a positive impact on their work lives" (p. 28), citing speed, rich communications, and organizational advantages (Wilkins, 2007). Furthermore, Lancaster, et al. (2007) found that instant messaging provides a more social experience than email communications. One of the inherent reasons for this must be the synchronous nature of the technology that allows instant feedback.

Primeaux and Flint (2004) concur and suggest that use of IM is desirable in the workplace due to its immediacy. IM allows for "[i]mmediate and spontaneous conversation between co-workers, precisely the type of communication that is becoming less and less available as email has become such a huge part of the corporate landscape...IM is the next best thing to standing in the hallway and discussing work" ( $p$. 5). Castelluccio (1999) calls IM email in real time, a communications revolution. Doyle (2003) sees instant messaging as a new and effective direct marketing tool, replacing email or direct mail.

Surprisingly, instant messaging has only been studied modestly in the literature, but the exploration of the factors influencing use of information technology behavior is an 
important topic for information technology researchers and practitioners (llie et al., 2005; Venkatesh \& Morris, 2000). Thus, IT practitioners should be very interested in models that explore the usage of a new and beneficial communications technology. The significantly smaller use of an Internet communications technology that has been perceived as having advantages over a more common technology is the primary motivation for this study. Factors that influence usage can be uncovered and can better explain why this technology has not achieved a comparable adoption level.

Several studies have looked at the reasons and motivations of why people use instant messanging. Ilie, et al. (2005) used diffusion theory to examine gender difference in perceptions and use of instant messaging. The authors determined that women value perceptions of ease of use and visibility more than men, while men value perceptions of relative advantage, the perceived utility and the perceived popularity or critical mass more than women. Women focus more on the social aspects, while men focus more on task completion. Debrand and Johnson (2008) also studied gender differences in email and IM and found no difference in perceptions or use of IM based on gender.

In a qualitative study by Kindred and Roper (2004), two focus groups comprised of college students were asked about their use of instant messaging. Students reported the primary reason for using IM was convenience, ease of use, privacy and the ability to multitask by engaging in multiple IM conversations. In a study of university students, Flanagan and Metzger (2006) determined that students primarily use IM for social entertainment and for social attention. Xue, Sankar, and Mbarika (2004/2005) found IM an important tool for virtual teams.

Wang, Hsu, and Fang (2005) note that, "the success of any information systems development depends on a combination of user acceptance and advancements in technology" (p. 15). If acceptance of instant messaging as a means of communication in business and in the population at large is desirable due to its favorable attributes, then understanding the factors influencing IM behavior is important to aid in deployment and use.

\section{Business Advantages}

Instant messaging offers a variety of advantages as an alternative method of communication in business. IM allows individuals to "communicate with their colleagues, customers and partners at a distance in real time" (para. 2), or synchronously, while avoiding high long distance telephone bills that apply during regular business hours (Shinder, 2005; Using Instant Messaging, n.d.). Shinder (2005) further asserts that IM continues to be the communications choice of many business professionals because it "provides more of a 'personal' link than e-mail, while being a bit less intrusive than the telephone" (para. 3). In addition, IM provides dual communication; one can be reading an email from a colleague or viewing a document on the company's intranet, while at the same time helping a customer via IM. Instant messaging helps to streamline customer service (DeHoyos, n.d.). Goveia (2008) asserts that the medium's "short, targeted notes can actually boost productivity" (para. 2 ). 
Another advantage of IM in the workplace is the appeal of "presence" (Lawton, 2003; Alexander, 2005; Bird, 2003; Goveia, 2008). Presence awareness is the "ability of an IM system to know if contacts are available to communicate" (Lawton, 2003, p. 14). IM allows the sender to know if the receiver is indeed available to receive and respond to an inquiry. E-mail, on the other hand, does not offer that capability. When a person is busy or away from her/his desk, they put up an IM message indicating as such. The advantage is that customers and colleagues do not have to play e-mail or telephone tag with each other. Employees who are telecommuters can not only utilize IM to communicate with customers and colleagues, but the organization can also use it to manage remote employees by way of online status monitoring (Krasne, 2009; Witts, 2009).

Other advantages include "interoperability with other IM services, archiving, auditing, and better security...videoconferencing, video and audio chat, sharing of text and multimedia files, and broadcasting of messages to subscribers" (Lawton, 2003, p. 14). Archiving and auditing features are important in industries such as banking and financial services, where Sarbanes Oxley requires companies to keep records of communications.

Enterprise instant messaging saves time and effort, improves customer service, and allows employees and customers to stay connected (Alexander, 2005). There is not the same lag time as experienced with e-mail; in addition, others have observed that IM cuts out unnecessary telephone chatting. It is a way to quickly communicate with a colleague, customer or supplier. Moreover, an outside sales force can stay connected to the office by utilizing mobile IM. Sometimes, depending on where the person is, private conversations with the home office or customers are just not feasible. Instant messaging helps to keep the conversation private. Goldsborough (1995) notes the speed and advantage of IM for online customer service.

Zhang and Fjermestad (2008) examined two small e-commerce businesses and as a result of interviews found the following uses of instant messaging in business - internal work collaboration, employee monitoring, customer service, external collaboration with business partners, internal coworker relationship building, and external relationship building with business partners.

Finally, the integration of corporate IM systems can save money on telephone usage, demand on email servers, and on the high cost of travel. "IM can only be an effective part of the communications structure if its use can be managed" (Bird, 2003, para. 3). Of course, all communications depend on the depth of content that needs to be conveyed and the need for synchronous versus asynchronous communications. Not all communications can be aided by instant messaging, but it can be a viable and useful tool for brief asynchronous communications. 


\section{Theory of Reasoned Action}

In order to explore influences on instant messaging behavior, a common model was selected: Theory of Reasoned Action developed by Ajzen and Fishbein (1980). The model uses four factors: attitude, subjective norm, intention, and behavior. TRA remains an important model for measuring user behavior (Brewer, Blake, Rankin \& Douglas, 1999; Lee, Tsai, Jih, 2006; Pak, 2000; Song \& Kim, 2006; Wooley \& Eining, 2006; Wu \& Liu, 2007). The model is shown in figure 1.

\section{Figure 1 Theory of Reasoned Action}

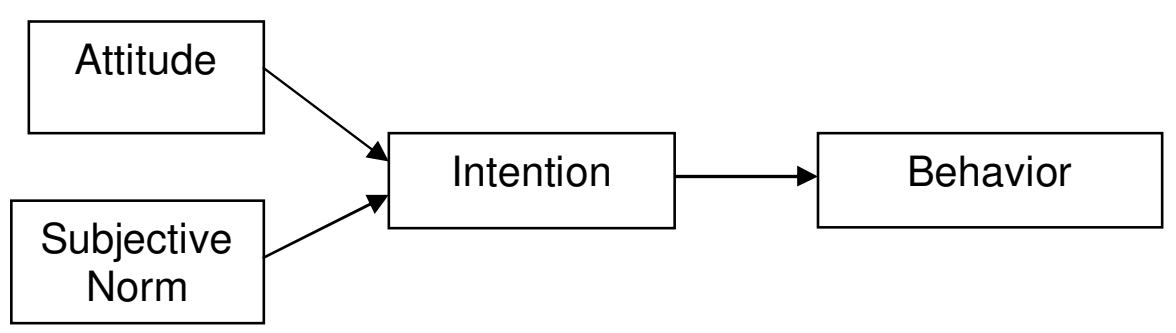

TRA was selected over other models (Theory of Planned Behavior and Technology Acceptance Model) similar to Wu and Liu (2007) because TRA has shown successful application to general consumer information technologies (Hansen, Jensen \& Solgaard, 2004; Njite \& Parsa, 2005) and organizational knowledge sharing (Hanson, et al., 2004; Kwok \& Gao, 2005/2006; Kwon \& Zmud, 1987). In addition, "Hsu and Lu (2004) found one important TAM (Technology Acceptance Model) construct -- perceived usefulness - did not directly affect behavioral intention, while the two TRA constructs -- attitude and subjective norms - did" (Wu \& Liu, 2007, p. 129). Intention to use is a common behavioral factor (Bahmanziari, Pearson, \& Crosby, 2003; Lu, Yu, \& Liu, 2005). Actual behavior generally follows intention in a variety of models (Bahmanziari, et al., 2003; Riemenschneider \& Hargrove, 2001). Theory of planned behavior also adds a measure of volitional control which is not suggested as an issue for instant messaging. TRA is being tested for this particular technology to verify its application for this technology. It is important that the model be tested in order to confirm applicability prior to development of specific action programs based on its theorized fit.

Definitions of the model's factors are as follow:

- Attitude is how we feel about the behavior and is generally measured as a favorable or unfavorable mind-set.

- Subjective norm is defined as how the behavior is viewed by our social circle or those who influence our decisions.

- Intention is defined as the propensity or intention to engage in the behavior.

- Behavior is the actual behavior itself. 


\section{Hypotheses}

Exploring the extent of fit between the TRA model factors and instant messaging, a series of hypotheses were developed. The traditional TRA model suggests influences and associations among factors that are tested in this study.

- Hypothesis one: Attitude toward instant messaging is positively associated with intention to use IM.

- Hypothesis two: Subjective norm of instant messaging is positively associated with intention to use IM.

- Hypothesis three: Attitude toward instant messaging is positively associated with use of IM.

- Hypothesis four: Subjective norm of instant messaging is positively associated with use of IM.

- Hypothesis five: Attitude toward instant messaging will be more strongly associated with intention than subjective norm.

- Hypothesis six: Intention to use instant messaging is positively associated with use of instant messaging.

- Hypothesis seven: Instant messaging technology will provide a model fit for behavioral intention and behavior.

All of the hypotheses are graphically represented in Figure 2 except for hypothesis five, which deals with relative strength of relationship, and hypothesis seven which deals with the overall model.

\section{Figure 2 Proposed Theory of Reasoned Action Model with Hypotheses}

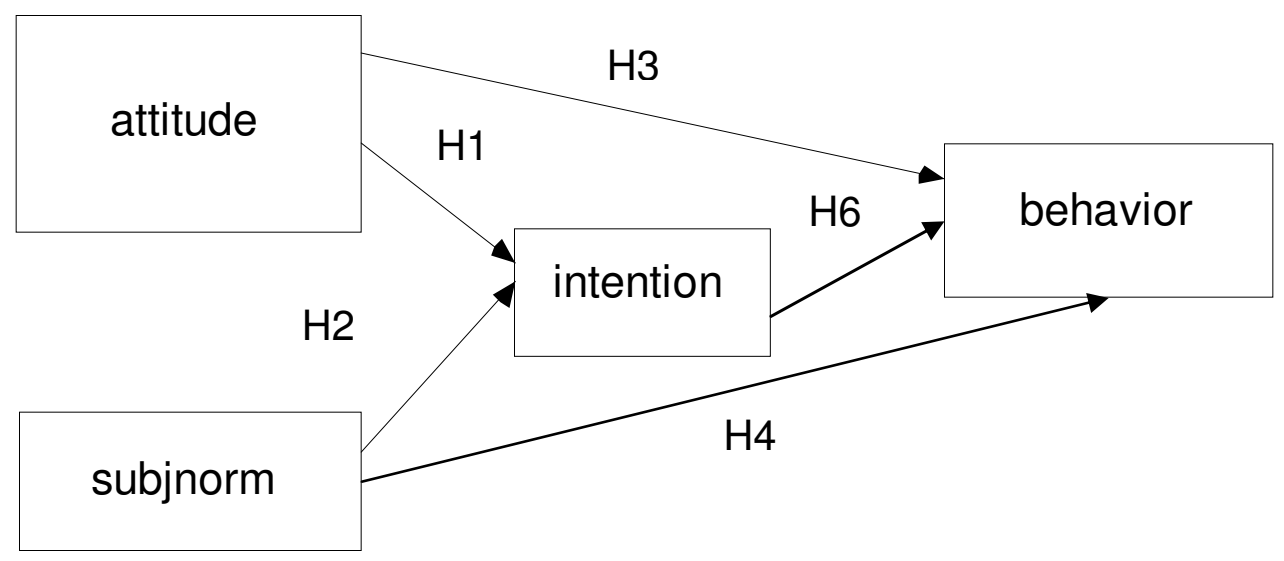




\section{Methodology}

A survey was prepared and pretested with a small group of students at a northeastern US university. The survey was modified based on preliminary tests and administered to 128 students at a small southeast US university. The survey was a survey of instant messaging intention and behavior. A subset of this study included specific questions that developed into TRA factors (table 1). The use of students is appropriate since this is the group who is most active in using this technology. Studying their usage can lead to factor determination and specific recommendations to encourage behavioral intention in others. Albaum and Peterson (2006) proport that students are "stakeholders, especially business students, who collectively constitute the future leadership of corporations."

\section{Table 1 Survey Questions and Factors}

\begin{tabular}{|c|c|c|}
\hline Factor & Abbreviation & Questions/Variables \\
\hline Attitude & ATTITUDE & Instant messaging is good. \\
\hline Attitude & ATTITUDE & Instant messaging is useful. \\
\hline Attitude & ATTITUDE & Instant messaging is worthwhile. \\
\hline Attitude & ATTITUDE & Instant messaging is helpful. \\
\hline Attitude & ATTITUDE & Instant messaging is valuable. \\
\hline Subjective Norm & SUBJNORM & $\begin{array}{l}\text { Most people who are important to me } \\
\text { think I should use instant messaging. }\end{array}$ \\
\hline Subjective Norm & SUBJNORM & $\begin{array}{l}\text { Close friends and family think it is a good } \\
\text { idea to use instant messaging }\end{array}$ \\
\hline Subjective Norm & SUBJNORM & $\begin{array}{l}\text { Important people want me to use instant } \\
\text { messaging }\end{array}$ \\
\hline Subjective Norm & SUBJNORM & $\begin{array}{l}\text { People who I listen to could influence me } \\
\text { to use instant messaging }\end{array}$ \\
\hline Subjective Norm & SUBJNORM & $\begin{array}{l}\text { Most people who are important to me } \\
\text { think I should use instant messaging. }\end{array}$ \\
\hline Behavioral Intention & INTENTION & I predict I will use instant messaging \\
\hline Behavioral Intention & INTENTION & I intend to use instant messaging \\
\hline Behavioral Intention & INTENTION & I plan to use instant messaging \\
\hline Actual System Use & BEHAVIOR & $\begin{array}{l}\text { I plan to use instant messaging in the } \\
\text { future. }\end{array}$ \\
\hline Actual System Use & BEHAVIOR & I currently use instant messaging. \\
\hline Actual System Use & BEHAVIOR & I will continue to use instant messaging. \\
\hline
\end{tabular}

For each of the relevant factors, survey questions modeled prior research. Subjective norm and attitude were based on Fitzmaurice (2005). Intention factor questions were 
modeled after llie, et al. (2005) and behavior was based on common usage terminology and piracy behavior factor in Woolley and Eining (2006).

The variables needed to test the theory of reasoned action include:

- Attitudes -The survey contained five questions that addressed respondents' attitudes toward instant messaging. The questions asked if they felt that instant messaging was useful, worthwhile and valuable.

- Subjective Norm - Subjective norm is defined as "the person's perception that most people who are important to him or her think he should or should not perform the behavior in question" (Ajzen \& Fishbein, 1980, p. 57). The survey contained four questions to measure subjective norm. Two of the questions asked included, "Most people who are important to me think I should use instant messaging" and "People who I listen to could influence me to use instant messaging."

- Behavioral Intentions - The behavioral intentions are the probability that the subject will use instant messaging. The survey questions asked the respondents if they plan to use instant messaging.

- Behavior - Behavior is the transmission of intention into action. The questions formulated in the survey asked if the respondents currently use, plan to use or will continue to use instant messaging.

The demographic mix shows a traditional college student population with $96 \%$ of the participants between the ages of 18 and 24 . The gender mix was slightly skewed with $64 \%$ females.

The questions measured a five point Likert scale with level of agreement from $1=$ strongly agree to $5=$ strongly disagree. SPSS 17 and AMOS 17 were used to analyze the data and test the proposed hypotheses. Factor analysis and scale reliability as well as structural equation modeling were conducted similar to Wooley and Eining (2006), and Moore (2000).

\section{Results}

Confirmatory factor analysis and scale reliability testing was used to determine the factors used in the model. All the factors were confirmed with one component determined and Eigenvalues over 1.0 which is generally seen as the level of acceptability (Moore, 2000). The ease of use five questions resulted in one component with an Eigenvalue over 1.0 at 3.601. The component matrix elements all were above 0.5 (minimum acceptable, Moore, 2000) and scale reliability provided a Cronbach's alpha of 0.874 , well above the minimum acceptable of 0.7 (Nunnally, 1978).

The five Usefulness questions also resulted in one factor with an eigenvalue over one, at 3.934. All components were over 0.5 and Cronbach's alpha was 0.892 . As noted, these are all well above minimum levels. 
Intention and its three variables clearly resulted in one factor with an eigenvalue over one, at 2.941. All components were over 0.98 and Cronbach's alpha was at 0.99 . These were certainly above minimum levels.

Finally, actual behavior was measured by three variables and it demonstrated one factor with an Eigenvalue over 1.0, at 2.701. All components were over 0.93 and Cronbach's alpha was 0.94 . In all cases and by all measures all factors met acceptable levels. Once the factors were determined, the results were analyzed in AMOS 17.0 to test the hypotheses and develop the model using structural equation modeling. Please note the $L$ designation after a variable denotes a latent variable.

Hypothesis one: proposed a positive association between attitude and intention to use IM. Theory of Reasoned Action (Ajzen \& Fishbein, 1980) suggests a positive and significant relationship between both attitude and subjective norm and intention. As shown in table 2, attitude toward instant messaging was positively associated with intention to use instant messaging. This correlation was significant at the $p<.001$ level. The coefficient was 0.419 . Attitude toward instant messaging did have an impact on intention to use IM. Hypothesis one was supported.

Table 2 Standardized Estimates (beta coefficients)

\begin{tabular}{|c|c|c|}
\hline & Standardized Estimates \\
\hline \multicolumn{2}{|c|}{ IntentionL <--- attitudeL } & .419 \\
\hline \multirow{2}{*}{\multicolumn{2}{|c|}{$\begin{array}{ll}\text { IntentionL }<--- & \text { SubjNormL } \\
\text { behaviorL<--- } & \text { IntentionL }\end{array}$}} & .284 \\
\hline & & .728 \\
\hline \multicolumn{2}{|c|}{ behaviorL <--- attitudeL } & .292 \\
\hline q3 & $<---$ attitudeL & .804 \\
\hline q4 & $<---$ attitudeL & .872 \\
\hline q5 & <--- attitudeL & .884 \\
\hline$q 6$ & <--- attitudeL & .909 \\
\hline q7 & $<---$ attitudeL & .798 \\
\hline q70 & $<---$ SubjNormL & .893 \\
\hline q71 & <--- SubjNormL & 842 \\
\hline q72 & <--- SubjNormL & .707 \\
\hline q73 & <--- SubjNormL & .666 \\
\hline q49 & <--- IntentionL & .974 \\
\hline q50 & $<---$ IntentionL & .992 \\
\hline q51 & <--- IntentionL & .990 \\
\hline q8 & <--- behaviorL & .914 \\
\hline q9 & <--- behaviorL & .910 \\
\hline $\mathrm{q} 10$ & <--- behaviorL & .950 \\
\hline
\end{tabular}

Note that all of the non-standardized estimates (not shown) were significant at $p<.001$ 
Hypothesis two: proposed that subjective norm is positively associated with intention to use IM. Subjective norm was found to have a positive and significant correlation with intention to use IM. This association was found to be at $p<.001$ as well with a coefficient of a lesser 0.284 . Hypothesis two was supported.

Hypothesis three: proposed a positive association between attitude toward instant messaging and use of IM. Gupta and Kim (2007) modified TRA and tested direct associations between base variables and use as opposed to only relationships through intention to use. They found many significant relationships. Our model tested the direct effect of both attitude and subjective norm on IM use. Table 2 shows an additional direct relationship, both positive and significant at $\mathrm{p}<.001$, between attitude toward IM and actual use of IM. Hypothesis three was supported.

Hypothesis four: proposed that subjective norm is positively associated with use of IM. It was also hypothesized that subjective norm would have a positive influence on use. This was not found to be the case with a $p$ value of 0.568 . This relationship was excluded from the model and results shown. There was no direct positive relationship between subjective norm and use of IM. Hypothesis four was not supported in this study.

Hypothesis five: proposed that attitude toward instant messaging will be more strongly associated with intention than subjective norm. Woolley and Eining (2006) found a stronger association in TRA between attitude and intention than subjective norm and intention as it relates to software piracy. As shown in table 2, attitude toward IM had a stronger association with behavior intention than subjective norm. The coefficient was nearly double. Hypothesis five was supported.

Hypothesis six: proposed a positive association between intention to use instant messaging and the use of IM. The original model of TRA (Ajzen \& Fishbein, 1980) found a strong positive relationship between intention and actual behavior. Gupta and Kim (2007) recently supported this relationship in a study of virtual communities. Our study supported this relationship at $p<.001$. Hypothesis six was supported.

Hypothesis seven: proposed that instant messaging technology will provide a model fit for behavioral intention and behavior. The inclusion of all factors into a comprehensive model was tested via AMOS 17.0. The model (excluding the direct relationship between subjective norm and behavior) provided a marginally acceptable overall fit. The RMSEA is 0.091 , above the recommended 0.06 or 0.08 (Stylianou \& Jackson (2007) but below the absolute cutoff of 0.1 (Browne \& Cudeck, 1993); the chi square divided by the degrees of freedom is 2.05, which is less than 3 , the cutoff suggested by Moore (2000) which means we can assume an acceptable model fit. These findings suggest that the model fits the data in the population from which the sample was drawn. The standardized estimates and squared multiple correlations are presented in figure 3 and table 3. Hypothesis seven was marginally supported. 
Figure 3 Theory of Reasoned Action Model with Standardized Estimates

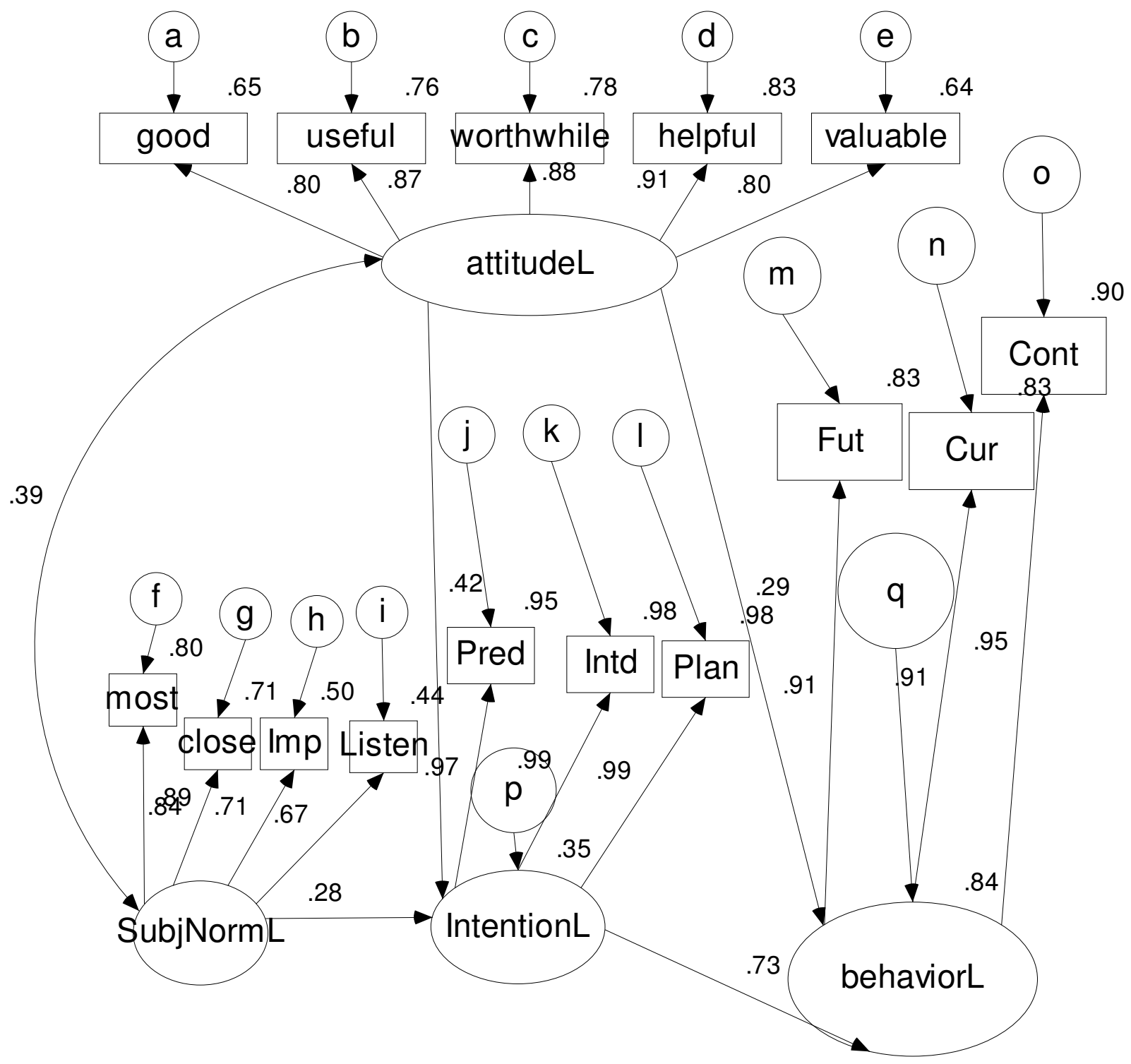

Table 3: Squared Multiple Correlations: (Group number 1 - Default model)

\begin{tabular}{|l|r|}
\hline & Squared Correlations \\
\hline IntentionL & .350 \\
behaviorL & .840 \\
\hline
\end{tabular}

\section{Limitations and Discussion}

As with any study, there are limitations to this study. First, the study examines primarily traditional students at one undergraduate university location. Results should be 
duplicated across other locations to confirm the preliminary findings of the study. In addition, only students were studied. Results may be different with non-students or with other age groups. Somewhat offsetting this limitation however, is the widespread use of instant messaging by this target group and age demographic. With a sizable penetration, factors influencing intention and usage can be studied due to the size of the participation.

Another limitation is the sample size. Though relatively large, the number of participants can be increased to improve reliability.

Finally, the study only examines the use of one model of human behavior. Though support and rationale for the use of Theory of Reasoned Action has been presented, there are other models which could be tested for adoption and behavior.

\section{Implications and Discussion}

Overall, it can be seen that Theory of Reasoned Action can be used as a model for instant messaging behavior. It has been proposed that instant messaging provides unique advantages over other electronic communications methods such as email. But despite these advantages, instant messaging is used much less frequently in both individual and business usage. Understanding the factors associated with intention and behavior associated with instant messaging suggests areas that can be focused on to increase instant messaging usage. First it was found that attitude toward instant messaging is positively associated with intention to use IM. In fact, it is the most important influencer of intention studied. Other researchers have suggested that education of users about favorable attributes of a product can change attitudes toward the product and thus increase intention to use the product (Bang, Ellinger, Hadjimarcou, \& Traichal, 2000; Xu \& Paulins, 2005). Education in schools and in the workplace on the benefits, advantages, and details of instant messaging is suggested to allow further penetration of this useful technology and improve overall communications. This could have significant positive cost and productivity improvements for businesses and organizations.

The second finding is that subjective norm is positively associated with intention to use IM. Subjective norm is the "perceived social pressure to perform or not perform an action" (Tarkiainen \& Sundqvist, 2005, p. 809). The study revealed that use of IM by others in their social group did have a significant influence on intention to use IM. The growth in IM use by students has been fueled by a social circle incentive. Those in the group have more social interaction and pressure exists to belong to this communication circle. This can expand through wider usage by the sampled population. This has important implications for practitioners. For businesses and organizations, there are fewer users and fewer pressures to use IM. Clearly though, concerted efforts on the part of management to both use and encourage the use of IM can increase intention to use $\mathrm{IM}$ and should be undertaken. 
The study next reviewed whether attitude had a direct influence on behavior rather than just behavior intention. It was found that attitude does have a direct influence on behavior, further emphasizing the need for education, training, and support if instant messaging usage is to be improved.

Conversely, subjective norm did not have a direct influence on behavior. Though subjective norm does influence intention, there was no significant direct influence on usage. Implications suggest that the social pressure provides a predisposition for behavior but then attitude provides the direct influence. This should be considered when designing education, training, and policy programs in organizations. They also suggest that mandates in the form of required usage could be unsuccessful in changing behavior unless there in an accompanying attitude program.

It was determined that attitude toward instant messaging was more strongly associated with intention to use IM than behavioral norm. This again supports the environment and education change program to influence attitude is more important than adopted policies in an organization.

As proposed in the original Ajzen and Fishbein (1980) model, intention to use instant messaging is positively associated with use of instant messaging. Many researchers have supported this relationship (Gupta et al., 2007; Shimp \& Kavas, 1984; Tarkiainen \& Sundqvist, 2005). Since our overall objective is to study and improve overall behavior, it was important that this relationship was established.

A final finding of the model development was that there was a significant covariance between subjective norm and attitude. This supports the development of a comprehensive program of social persuasion including a favorable climate and view of IM by itself as well as by peer pressure. This program plus education and training should ultimately improve use of instant messaging in businesses as well as the population at large.

\section{Conclusion}

Overall this study has provided significant factors that influence and model instant messaging intention and behavior. We see this as the start of an exploration of ways to increase and improve penetration of this advantageous communications technology. Studies can be undertaken to confirm these findings with larger and more diverse sample groups, but preliminary findings suggest that instant messaging does adhere to the theory of reasoned action model and is thus subject to efforts to improve behavior through attention to the significant influencing factors of attitude, subjective norm, and intention. The authors welcome efforts to assist in this fertile research area. 


\section{References}

Ajzen, I., \& Fishbein, M. (1980). Understanding Attitudes and Predicting Social Behavior. Englewood Cliffs: Prentice-Hall, Inc.

Albaum, G., \& Peterson, R. (2006). Ethical attitudes of future business leaders: Do they vary by gender and religiosity? Business and Society, 45(3), 300-321.

Alexander, P. (2005, November 14). Should your business use instant messaging? Retrieved July 9, 2009, from Entrepreneur.com: http://www.entrepreneur.com/technology/techtrendscolumnistpeteralexander/artic le81050.html

AMA. (2006). 2006 Workplace E-Mail, Instant Messaging \& Blog Survey. American Management Association (AMA) and The ePolicy Institute.

Bahmanziari, T., Pearson, M. J., \& Crosby, L. (2003). Is trust important in technology adoption? A policy capturing approach. The Journal of Computer Information Systems, 43(4), 46-54.

Bang, H. K., Ellinger, A., Hadjimarcou, J., \& Traichal, P. (2000). Consumer concern, knowledge, belief, and attitude toward renewable energy: An application of the reasoned action theory. Psychology \& Marketing, 17, 449-468.

Bird, D. (2003, June 10). Instant Messaging, Part II: Does IM Have a Place in Your Business. Retrieved July 9, 2009, from IntranetJournal.com: http://www.intranetjournal.com/articles/200306/ij_06_10_03a.html

Brewer, J., Blake, A., Rankin, S., \& Douglas, L. (1999). Theory of reasoned action predicts milk consumption in women. Journal of the American Domestic Association, 99(1), 39-44.

Browne, M., \& Cudeck, R. (1993). Testing structural equation models. (K. A. Bollen, \& J. S. Long, Eds.). Newbury Park: Sage Publications.

Castelluccio, M. (1999). E-mail in real time. Strategic Finance, 81(3), 34-37.

Debrand, C. C., \& Johnson, J. J. (2008). Gender differences in email and instant messaging: A study of undergraduate business information systems students. The Journal of Computer Information Systems, 48(3), 20-30.

DeHoyos, B. (n.d.). IM for Business: Choosing an Enterprise IM for Your Work Life. Retrieved July 9, 2009, from About.com: Instant Messaging: http://im.about.com/od/imforbusiness/a/enterpriseims.htm

Doyle, S. (2003). Is instant messaging going to replace SMS and e-mail as the medium of choice? Journal of Database Marketing \& Customer Strategy Management, 11(2), 175-182

Fitzmaurice, J. (2005). Incorporating consumers' motivations into the theory of reasoned action. Psychology \& Marketing, 22(11), 911-929.

Flanagan, A. J., \& Metzger, M. J. (2006). Internet use in the contemporary media environment. Human Communication Research, 27(1), 153-181.

Goldsborough, R. (2004). Managing the risks and rewards of instant messaging. Black Issues in Higher Education, 21(13), 36.

Goldsborough, R. (2005). Instant messaging for marketing? Black Issues in Higher Education, 22(1), 41.

Goveia, T. (2008, October 13). Communications: Faster and shorter. Canadian Business, 81(17), 25-26. 
Gupta, S., \& Kim, H. W. (2007). Developing the commitment to virtual community: the balanced effects of cognition and affect. Information Resources Management Journal, 20(1), 28-45.

Hansen, T., Jensen, J., \& Solgaard, H. (2004). Predicting onlne grocery buying intention: A comparison of the theory of reasoned action adn the theory of planned behavior. International Journal of Infomation Management, 24(6), 539550.

Hsu, C-L, \& Lu, H-P. (2004). Why do people play on-line games? An extended TAM with social influences and flow experience. Information \& Management, 41(7), 853-868.

Ilie, V., Van Slyke, C., Green, G., \& Lou, H. (2005). Gender difference in perception and use of communication technologies: A diffusion of innovation approach. Information Resources Management Journal, 18(3), 13-31.

Kindred, J., \& Roper, S. L. (2004). Making connections via Instant Messenger (IM): Student use of IM in the maintenance of personal . Qualitative Research Reports in Communication, 45-54.

Krasne, A. (2009, April). Manage telecommuters easily and securely. PC World, 27(4), pp. 35-36.

Kwok, S. H., \& Gao, S. (2005/2006). Attitude towards knowledge sharing behavior. The Journal of Computer Information Systems, 46(2), 45-51.

Kwon, T., \& Zmud, R. (1987). Unifying the fragmented models of information systems implementation. Critical Issues in Information Systems Research (pp. 227-251). New York, NY: Wiley.

Lancaster, S., Yen, D., Huang, A., \& Hung, S. (2007). The selection of instant messaging or e-mail: College student's perspective for computer communication. Information Management \& Computer Security, 15(1), 5-22.

Lawton, G. (2003). Instant messaging puts on a business suit. Computer, 36(3), 14-16.

Lee, S.F., Tsai, Y. C., \& Jih, W. J. (2006). An Empirical Examination of Customer Perceptions of Mobile Advertising. Information Resources Management Journal, 19(4), 39-55.

Lu, J., Yu, C.-S., \& Liu, C. (2005). Facilitating conditions, wireless trust and adoption intention. The Journal of Computer Information Systems, 46(1), 17-24.

Moore, J. E. (2000). One road to turnover: an examination of work exhaustion in technology. MIS Quarterly, 24(1), 141-167.

Njite, D., \& Parsa, H. (2005). Structural equation modeling of factors that influence consumer internet purchase intentions of services. Journal of Services Research, 24(6), 43-59.

Nunnally, J. (1978). Psychometric Theory. New York: McGraw-Hill.

Pak, H. S. (2000). Relationships among attitudes and subjective norms: testing the theory of reasoned action across cultures. Communication Studies, 51(2), 162175.

Pew Internet Life. (2004). How Americans use Instant Messaging. Retrieved July 2008, from http://www.perinternet.org/pdfs/PIP_instantmessage_report.pdf

Primeaux, R., \& Flint, D. (2004). Instant messaging: Does it belong in the workplace? Intellectual Property \& Technology Law Journal, 16 (11), 5-7. 
Rainie, L., \& Horrigan, J. (2005). A Decade of Adoption: How the Internet has Woven itself into American Life. Pew Internet Organization.

Riemenschneider, C. K., \& Hargrove, B. C. (2001). Explaining software development tool use with the technology acceptance model. The Journal of Computer Information Systems, 41(4), 1-8.

Rogers, E. (1995). Diffusion of Innovations, 4th Edition. New York, NY: Free Press.

Shimp, T., \& Kavas, A. (1984). The theory of reasoned action applied to coupon usage. The Journal of Consumer Research, 11(3), 795-809.

Shinder, D. (2005, April 6). Instant Messaging: Does it have a place in business networks? Retrieved July 9, 2009, from WindowSecurity.com: http://www.windowsecurity.com/articles/Instant-Messaging-BusinessNetworks.html

Song, J., \& Kim, Y. J. (2006). Social influence process in the accptance of a virtual community service. Information Systems Front, 8, 241-152.

Stylianou, A. C., \& Jackson, P. J. (2007). A comparative examination of individual differences and beliefs on technology usage: Gauging the role of IT. The Journal of Computer Information Systems, 47(4), 11-18.

Tarkiainen, A., \& Sundqvist, S. (2005). Subjective norms, attitudes and intentions of finnish consumers in buying organic food. British Food Journal , 107(11), 808822.

Using Instant Messaging for Business. (n.d.). Retrieved July 9, 2009, from AllBusiness.com: http://www.allbusiness.com/technology/computer-softwareproductivity-applications/1229-1.html

Venkatesh, V., \& Morris, M. (2000). Why don't we ever stop to ask directions? Gender, social influence, and their role in technology, acceptance model. MIS Quarterly, 24(1), 115-139.

Wang, C.-C., Hsu, Y., \& Fang, W. (2005). Acceptance of technology with network externalities: an empirical study. Journal of Information Technolgy Theory and Application, 6(4), 15-28.

Wilkins, J. (2007). R U ready for IM? Information Management Journal, 41(3), 3-27.

Witts, P. (2009, February 19). Instant messaging. BRW, 31(7), 34.

Woolley, D., \& Eining, M. (2006). Software piracy among accounting students: A longitudinal comparison of chance and sensitivity. Journal of Information Systems, 20(1), 49-63.

Wu, J., \& Liu, D. (2007). The effects of trust and enjoyment on intention to play online games. Journal of Electronic Commerce Research, 8(2), 128-140.

Xu, Y., \& Paulins, V. A. (2005). College students' attitudes toward shopping online for apparel products: Exploring a rural versus urban campus. Journal of Fashion Marking and Management, 9(4), 420-433.

Xue, Y., Sankar, C. S., \& Mbarika, V. W. (2004/2005). Information technology outsourcing and virtual team. The Journal of Computer Information Systems, 45(2), 9-16.

Zhang, S., \& Fjermestad, J. (2008). Instant messaging: observations from two small e-commerce businesses. Journal of Enterprise Information Management, 21(2), 179-197. 